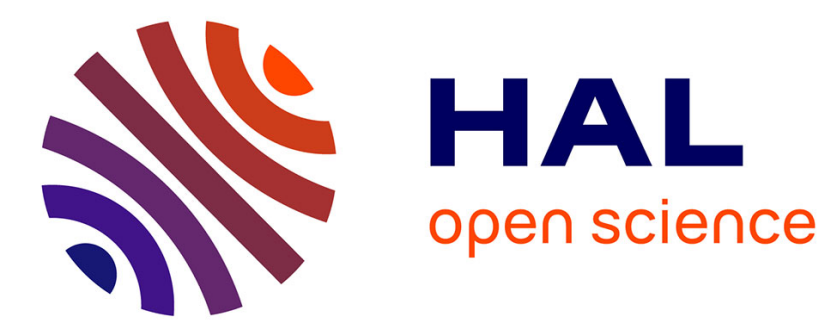

\title{
Hydrostatic and osmotic pressure study of the hairpin ribozyme.
}

Guy Hervé, Sylvia Tobé, Thomas Heams, Jacques Vergne, Marie-Christine

Maurel

\section{- To cite this version:}

Guy Hervé, Sylvia Tobé, Thomas Heams, Jacques Vergne, Marie-Christine Maurel. Hydrostatic and osmotic pressure study of the hairpin ribozyme.. BBA - Biochimica et Biophysica Acta, 2006, 1764(3), pp.573-7. 10.1016/j.bbapap.2006.01.020 . hal-00021985

\section{HAL Id: hal-00021985 https://hal.science/hal-00021985}

Submitted on 30 Mar 2006

HAL is a multi-disciplinary open access archive for the deposit and dissemination of scientific research documents, whether they are published or not. The documents may come from teaching and research institutions in France or abroad, or from public or private research centers.
L'archive ouverte pluridisciplinaire HAL, est destinée au dépôt et à la diffusion de documents scientifiques de niveau recherche, publiés ou non, émanant des établissements d'enseignement et de recherche français ou étrangers, des laboratoires publics ou privés. 


\title{
HYDROSTATIC AND OSMOTIC PRESSURE STUDY OF THE HAIRPIN RIBOZYME
}

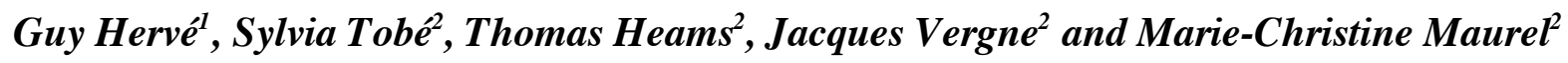 \\ 1 : Laboratoire Proteins ; Biochimie Structurale et Fonctionnelle, FRE CNRS 2852, Université Pierre et Marie \\ Curie-Paris 6, 96 Bd Raspail, 75006, France gherve@ccr.jussieu.fr \\ 2 : Laboratoire de Biochimie de l'Evolution et Adaptabilité Moléculaire, Institut Jacques Monod, Université \\ Pierre et Marie Curie-Paris 6, Tour 43, 2 place Jussieu, 75251, Paris cedex 05, France maurel@ijm.jussieu.fr
}

Corresponding author: Guy Hervé, gherve@ccr.jussieu.fr

Key words : High pressure, osmotic pressure, hairpin ribozyme, RNA world.

\begin{abstract}
The recent discovery of numerous catalytically active RNAs in various living species as well as the in vitro selection of a large series of RNA aptamers able to bind specifically various molecules such as metabolites and co-factors, emphasize the adaptability of RNAs through the plasticity of their secondary structure . Furthermore, all these observations give support to the «RNA world » hypothesis as a step in the primitive development of life on Earth. On this background, we used high pressure to study the mechanism of action of a model hairpin ribozyme which exhibits self-cleavage and ligation. The activation volume $\left(\Delta \mathrm{V}^{*}\right)$ of the cleavage reaction $(34 \pm 4 \mathrm{ml} / \mathrm{mole}$ ) indicates that an important compaction of the RNA molecule occurs during the reaction and must be accompanied by a significant movement of water molecules . Indeed, such a release of $78 \pm 4$ water molecules per RNA molecule could be measured by complementary osmotic shock experiments. These results are consistent with the information provided by the structural studies which indicate that two loops of the RNA molecule should come into contact for the reaction to occur. The high pressure study of a modified form of the ribozyme whose activity is strictly dependent on the presence of adenine as a co-factor should bring some information about the structural significance of this important $\Delta \mathrm{V}^{\ddagger}$ of activation.
\end{abstract}

\section{Introduction}

Several lines of evidence lead to the hypothesis that in the early steps of the development of life on Earth, RNA preceded the DNA-protein world (1).This hypothesis already suggested by Woese, Crick and Orgel in the sixties (2-4) proposes that modern life arose from molecular ancestors in which RNA molecules both stored genetic information and catalyzed biochemical reactions (5-7). In this context it is interesting to note that the deoxyribonucleotides, precursors of DNA, are synthesized from ribonucleotides and that thymine, a specific constituent of DNA, results from the methylation of uracile, an RNA specific base. The DNA replication starts with the synthesis of an RNA primer, suggesting that DNA replication could be a "modified» transcription process. Furthermore, we know that individual ribonucleotides are key signalling molecules and that coenzyme derivatives are essential in modern metabolism $(8,9)$. Numerous RNAs able to bind specifically various metabolites and co-factors were selected in vitro, illustrating the remarkable plasticity and adaptability of RNA molecules and of their secondary structure, an important property which, most probably, played a role during the early development of life (10-11).

In the recent years a series of catalytically active RNA molecules were identified in various organisms (12). That includes, the ribozyme catalysing the peptide bond formation in the 
ribosome $(13,14)$, the self-cleaving RNAs family, groups I and II introns, the spliceosome and the Ribonuclease P (15). Some of them might be relics of the ancient metabolism. Among the major natural ribozymes, the hairpin, hammerhead and hepatitis delta virus ribozymes constitute the family of small self-cleaving RNAs found in RNA viruses, satellite RNAs and viroïds (16).

Recently, reports by Di Giulio gave support to the hypothesis that life emerged and developped in the deep-sea volcanic environments characterized by a rich chemical composition, heat and pressure $(17,18)$. The comparison of the genomes of very close barophilic and nonbarophilic Archae allowed this author to demonstrate a significant relationship between the amino acids predominant in the proteins from barophiles and the number of codons attributed to these amino acids, suggesting that the genetic code organization took place under high pressure.

In the investigations reported here the hairpin ribozyme self-cleavage reaction was studied under high pressure, not only in view of the hypothesis that life emerged on Earth under pressure, but also on the basis that this physical parameter can provide specific information concerning large conformational changes in biomacromolecules.

\section{The hairpin ribozyme.}

The hairpin ribozyme was first observed in the negative strand of the tobacco ringspot virus satellite RNA ((-)s TRSV) $(19,20)$ and has been found since in two other pathogenic plant satellite viruses : the arabis mosaic virus and the chicory mottle virus satellites (sARMV and sCYMV).

The hairpin ribozyme used in the present study is a fully active shortened form of the tobacco ringspot virus in which the new extremities were modified for the purpose of amplification (PCR and expression). The preparation of this model ribozyme is described in (11), and its structure is shown in figure 1 . It consists of four stem regions (A, B, C, D) connected through a four way junction, the scissile phosphate being in A loop. Mutagenesis and modification interference studies showed that the nucleotides essential for the activity reside in both stems A and B (21, $22)$. It is possible to reconstitute a catalytically active ribozyme by synthesizing stems A and B separately and then mixing them $(23,24)$. The structures of the isolated stems A (25) and B (26) were determined by NMR. These studies showed that both of them present an irregular helical central portion with non-canonical base pairs, flanked on both sides by standard base-paired helices.

\section{The hairpin ribozyme mechanism}

As shown in figure 1, the nucleotides G8, A9, A10, G11, G21, A22, A23, A24, C25, A38, A40, U41, U42, A43, C59, G61, and U62 are absolutely required for the reaction to occur (27). With the exception of G11, all these essential nucléotides lie within nonhelical segments $(28,29)$. Although the four first ones are located in loop A close to the site of cleavage, G21 to A43 are located in loop B. This observation already suggested that loops A and B must come close together during catalysis, an important conformational change. Indeed, the crystallographic structure of a ribozyme construct bound to an inhibitor (30), showed such a docking, along with modifications in the secondary structure of the loops $\mathrm{A}$ and $\mathrm{B}$, including base-pairing modifications in the non-canonical part. The ribozyme reaction was described as requiring the presence of $\mathrm{Mg}^{++}$. However, the catalytic activity is maintained in the presence of a wide variety of cations or positively charged molecules such as $\mathrm{Mn}^{++}, \mathrm{Co}^{++}, \mathrm{NH}_{4}^{+}$, polyamines and aminoglycoside antibiotics . It seems therefore that divalent cations stabilize the functional structure of the ribozyme through non-specific electrostatic interactions, but are not required for the catalytic chemistry itself (31-34). 


\section{High pressure study of the ribozyme reaction}

The involvement of such an important conformational change during the reaction catalyzed by the hairpin ribozyme as well as the probability that life emerged and developped under pressure, prompted us to study the influence of hydrostatic pressure on this reaction. This method is particularly performant in the study of hydration changes occuring in both proteins and nucleic acids during large conformational changes or dissociation-association processes (35, 36). In the case of the ribozyme studied here, the important conformational change resulting from the docking of loops $\mathrm{A}$ and $\mathrm{B}$ would be associated to a positive volume change resulting from the decrease of the surface of the molecule exposed to the solvent (35). These experiments were performed using the previously described apparatus which allows injection, stirring and sampling without releasing the pressure (37). The preparation of the ribozyme and the experimental conditions were also previously described (38). It appeared that pressure has a drastic effect on the rate of the ribozyme reaction. Figure 2 shows the kinetics observed when varying the pressure from 0.1 to $200 \mathrm{MPa}$. Treatment of these progress curves as exponentials allowed to calculate the values of the rate constant. Figure $3 \mathrm{a}$ shows the variation of this rate constant as a function of pressure. It appears that the reaction involves an important positive activation volume $\left(\Delta \mathrm{V}^{z}\right)$ which was calculated to be $34 \pm 5 \mathrm{ml} / \mathrm{mol}$. from the slope of the curve This result indicates that during the formation of the transition state of the reaction the ribozyme condenses on itself reducing it surface exposed to the solvent. In a similar way, Figure $3 b$ shows the variation of the equilibrium constant of the reaction as a function of pressure. From the slope of the curve a volume change $(\Delta \mathrm{V})$ of $17 \pm 4.5 \mathrm{ml} / \mathrm{mol}$ can be calculated for the forward reaction. The significance of this result will be discussed further.

It has been verified that this influence of pressure on the rate constant is fully reversible and does not result from an irreversible alteration of the ribozyme structure. This is shown in figure 4 and confirmed by the values of the rate constant also reported in this figure. Thus, the influence of pressure on the rate constant corresponds to a fully reversible conformational transition.

\section{Influence of osmotic pressure on the ribozyme reaction}

The influence of pressure on the rate constant of the reaction catalyzed by the hairpin ribozyme indicates that this reaction involves $a$ transient condensation of the RNA molecule with a decrease of the surface exposed to the solvent. Therefore, this step must be acompagnied by a release of water molecules. To test this conclusion the influence of osmotic pressure on the rate of the reaction was determined as proposed by Parsegian et al.(39), and the result obtained is shown in figure 5. Indeed, osmotic pressure has an important positive effect on the rate of the reaction and from the slope of the variation of the rate constant as a function of osmotic pressure a release of $78 \pm 4$ water molecules by RNA molecule can be calculated.

\section{A hairpin ribozyme variant requiring adenine as a cofactor}

By modification of the minimal hairpin ribozyme used in the above described experiments, a variant, called ADHRI, whose activity strictly depends on the presence of adenine as a co-factor was obtained (11). This variant differs from the wild type form by four bases substitutions : U20, A36, G38 and C39 instead of A20, G36, A38 and U39. The apparent $\mathrm{K}_{\mathrm{d}}$ for adenine is 7.6 $\mathrm{mM}$. The preliminary results obtained through the use of high pressure suggest that the $\Delta \mathrm{V}^{\neq}$of activation for the reaction catalyzed by this modified ribozyme is of the same order of magnitude than that of the wild type ribozyme.

\section{Conclusions and perspectives}

All the informations obtained through these high pressure experiments are assembled in figure 6 . The results obtained show that the reaction catalyzed by the hairpin ribozyme implies a positive apparent $\Delta \mathrm{V}^{\neq}$of activation of $34 \pm 5 \mathrm{ml} / \mathrm{mol}$ which indicates that during the reaction the 
hairpin ribozyme must condense on itself (from conformation a to conformation b). This conclusion is in accordance with the fact that the bases directly involved in the reaction are localized in both loops A and B $(21,22)$, implying that these two loops must come into contact during the reaction. It is also consistent with the crystallographic structure of the ribozyme bound to a competitive inhibitor of the reaction (30). Such a domain closure or docking must be accompagnied by a decrease of the hydration of the RNA molecules and the release of water molecules. The osmotic pressure experiments reported above confirm this prediction and indicate that $78 \pm 4$ water molecules are expelled per RNA molecule during the reaction. It is interesting to remark that this value is in reasonable agreement with the fact that the surface of the ribozyme which is exposed to the solvent decreases by $1570 \AA^{2}$ upon docking (30). The variation of the apparent equilibrium constant of the reaction as a function of pressure indicate that the forward reaction is accompagnied by a $17 \pm 4.5 \mathrm{ml} / \mathrm{mol}$ positive $\Delta \mathrm{V}$ (fron conformation a to conformation d). This unexpected observation suggests that at the end of the reaction the cleaved ribozyme molecule is significantly less hydrated than the uncleaved molecule. Such a conformation might correspond to the intermediary conformation between the open an docked states whose existence was recently reported (40). Since the reaction is started by the addition of $\mathrm{Mg}^{++}$, the apparent $\Delta \mathrm{V}^{\ddagger}$ of activation measured in the case of the wild type might reflect both the docking step and the formation of the transition state. The high pressure study of the adenine requiring mutant of the ribozyme might allow to differenciate these steps since, in this case, the reaction can be started either by adding magnesium to the ribozyme-adenine complex or by adding adenine to the ribozyme-magnesium complex. This investigation might also provide some information about the mechanism of activation by adenine, an interesting aspect since, most probably, such processes of ribozyme activation by cofactors operated in the « RNA world ».

\section{Acknowledgements}

This investigation was supported by the Centre National de la Recherche Scientifique, the Université Pierre et Marie Curie, the Groupement de Recherche «Exobiologie », and the Centre National d'Etudes Spatiales

\section{References}

(1) W. Gilbert . The RNA World, Nature 319 (1986) 618.

(1) C.R. Woese. On the evolution of the genetic code, Proc. Natl. Acad. Sci. U.S.A. 54 (1965) 1546-1552.

(2) F.H. Crick . The origin of the genetic code, J. Mol. Biol. 38 (1968) 367-379.

(3) L.E. Orgel. Evolution of the genetic apparatus, J. Mol. Biol. 38 (1968) 381-393.

(4) R.F. Gesteland, T.R. Cech, J.F. Atkins eds. The RNA world ; ${ }^{\text {nd }}$. Edition, Cold Spring Harbor Laboratory Press, (1999).

(5) M.C. Maurel. RNA in Evolution, J. Evol.Biol. 5 (1992) 173-188.

(6) M.C. Maurel, A.L. Haenni. The RNA world : hypothesis, facts and experimental results. Lectures in Astrobiology, Barbier, B., Gargaud, M. Martin, H. and Reisse ,J. eds, Springer Verlag, (2005) 557-581.,. Nature, structural biology, 7 (2000) 831-833.

(7) M.G. Caprara, T.W. Nilsen. RNA: Versatility in form and function, Nature, structural biology, 7 (2000) 831-833.

(9)A. Kun, M.C. Maurel, M. Santos, A. Szathmary. Fitness landscapes, error thresholds and cofactors in aptamer evolution. In: Aptamers and synthetic catalytically active oligonucleotides;Identification and Adaptation.Kusmann,S. ed. Wiley Vch. In press

(10) G.F. Joyce . The antiquity of RNA-based evolution, Nature 418 (2002) 214-220. 
(11) M. Meli, J. Vergne, M.C. Maurel. In vitro selection of Adenine-dependent Hairpin Ribozymes. J. Biol. Chem.. 278 (2003) 9835-9842.

(12) J.A. Doudna, T.R .Cech. The chemical repertoire of natural ribozymes, Nature, 418 (2002) 222-227.

(13) M.M. Yusupov, G.Z. Yusupova, A. Baucom, K. Lieberman, T.N. Earnest, J.H .Cate H.F. Noller. Crystal structure of the ribosome at 5.5 A resolution. Science 292 (2001) 883-896.

(13) K.M. Parnell, A.C. Seila, S.A. Strobel. Evidence against stabilization of the transition state oxyanion by a pKa-perturbed RNA base in the peptidyl transferase center. Proc. Natl. Acad. Sci. USA. 99 (2002) 11658-11663.

(14) S. Altman, D. Wesolowski, C. Guerrier-Takada, Y. Li, RNAse P cleaves transient structures in some riboswitches, Proc. Natl. Acad. Sci. USA, in press.

(15) Y. Li, S. Tobé, A. Chabauty, M.C. Maurel, Modern and ancient RNA world. in: Plant Genome; Biodiversity and Evolution, Vol. 2B: Lower Groups, Raju Primlani Ed. In press.

(16) M. Di Giulio, A comparison of proteins from Pyrococcus furiosus and Pyrococcus abyssi : barophily in the physical properties of amino acids and in the genetic code. Gene, 346 (2005) 1-6.

(17) M.Di Giulio, The ocean abyssus witnessed the origin of the genetic code. Gene, 346 (2005) 7-12.

(18) J.M. Buzayan, A. Hampel, G. Bruening, Nucleotide sequence and newly formed phosphodiester bond of spontaneously ligated satellite tobacco ringspot virus RNA, Nucleic Acids Res. 14 (1986) 9729-9743.

(19) J.M.Buzayan, P.A.Feldstein, G.Bruening, F. Eckstein, RNA mediated formation of a phosphorothioate diester bond. Biochem. Biophys. Res. Commun. 156 (1988) 340347.

(20) M.J. Fedor, The catalytic mechanism of the hairpin ribozyme. Bioch. Soc. Trans. 30 (2002) 1109-1115.

(21) S.P. Ryder, S.A. Strobel, Comparative analysis of hairpin ribozyme structures and interference data. Nucleic Acids Res. 30 (2002) 1287-1291.

(22) S.E. Butcher, J.E. Heckman, J.M.Burke. Reconstitution of hairpin ribozyme activity following separation of functional domains. J. Biol. 1995, 270 (1995) 29648-29651.

(23) C. Shin, J.N. Choi, S.I. ,Song, J.T. Song, J.H.Ahn, J.S. Lee, Y.D.Choi. The loop B domain is physically separable from the loop A domain in the hairpin ribozyme. Nucleic Acids Res. 24 (1996) 2685-2689.

(24) Z. Cai, I.J.Tinoco. Solution structure of loop A from the hairpin ribozyme from tobacco ringspot virus satellite, Biochemistry 35 (1996) 6026-6036.

(25) S.E. Butcher, F.H.T.Allain, J. Feigon, Solution structure of the loop B domain from the hairpin ribozyme. Nature, Struct. Biol. 6 (1999) 212-216.

(26) M.J. Fedor, Structure and functionof the hairpin ribozyme, J. Mol. Biol. 297 (2000) 269-291.

(27) A. Berzal-Herranz, S. Joseph, B.M. Chowrira, S. E. Butcher, J.M. Burke, Essential nucleotide sequences and secondary structure elements of the hairpin ribozyme, EMBO J. 12 (1993) 2567-2574.

(29) A. Barroso-Deljesus, A. Berzal-Herranz, Selection of targetsand the most efficient hairpin ribozymes,for inactivation of mRNAs using a self-cleaving RNA library, EMBO reports 21 (2001) 1112-1118.

(30). P.B. Rupert, A.R. Ferré-D’Amaré, Crystal structure of a hairpin ribozymeinhibitor complex with implications for catalysis, Nature 410 (2001) 780-786. 
(31) S.M. Nesbitt, H.A.Erlacher, F.J.Fedor, The internal equilibrium of the hairpin ribozyme: temperature, ion and pH effects, J. Mol. Biol. 286 (1999) 1009-1024.

(32) S.M. Nesbitt, F.Hegg, F.J. Fedor, An anusual pH-independent and metal-ionindependent mechanism for hairpin ribozyme catalysis, Chem.Biol. 4 (1997) 619-630.

(33) K.J. Young,F. Gill, J.A.Grasby, Metal cations play a passive role in the hairpin ribozyme catalyzed reaction, Nucleic Acids Res. 25 (1997) 3760-3766.

(34) T.J. Wilson, D.M. Lilley, Metal ion binding and the folding of the hairpin ribozyme, RNA 8 (2002) 587-600.

(35) K.Heremans, High pressure effects on proteins and other biomolecules, Annu. Rev. Biophys. Bioeng. 11, (1982) 1-21.

(36) G. Weber, H. Drickamer, The effect of high pressure upon proteins and other biomolecules, Quarterly. Rev.Biophys. 16,(1983) 89-112.

(37) G. Hui Bon Hoa,G. Hamel, G. Weill, G. Hervé, A reactor permitting injection and sampling for steady state studies of enzymatic reactions at high pressure; tests with aspartate trancarbamylase., Analyt. Biochem. 187 (1990) 258261.

(38) S. Tobé, T. Heams, J. Vergne, G. Hervé, M.C.Maurel, The catalytic mechanism of hairpin ribozyme studied by hydrostatic pressure. Nucleic Acids. Res. 33 (2005) 2557-2564.

(39) V. Parsegian, R. Rand, H. Fuller, D.Rau, Osmotic stress for the direct measurement of intermolecular forces. Methods Enzymol. 127 (1986) 400-416.

(40) E. Tan, M. Wilson, M. Nahas, R. Clegg, D. Lilley, T. Ha, A four-way junction accelerates hairpin ribozyme folding via a discrete intermediate, Proc. Natl. Acad. Sci. USA 100 (2003) 9308-9313. 


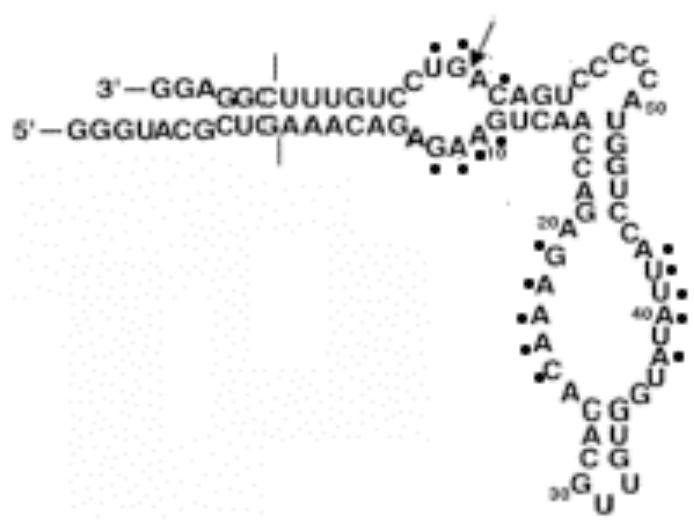

\section{Figure 1}

Wild-type hairpin construct used in this study. The arrow indicates the cleavage site. The dots identify the bases strictly required for the catalytic activity. The 5' and 3' extensions added for hybridization with replication primers are marked with dashes.

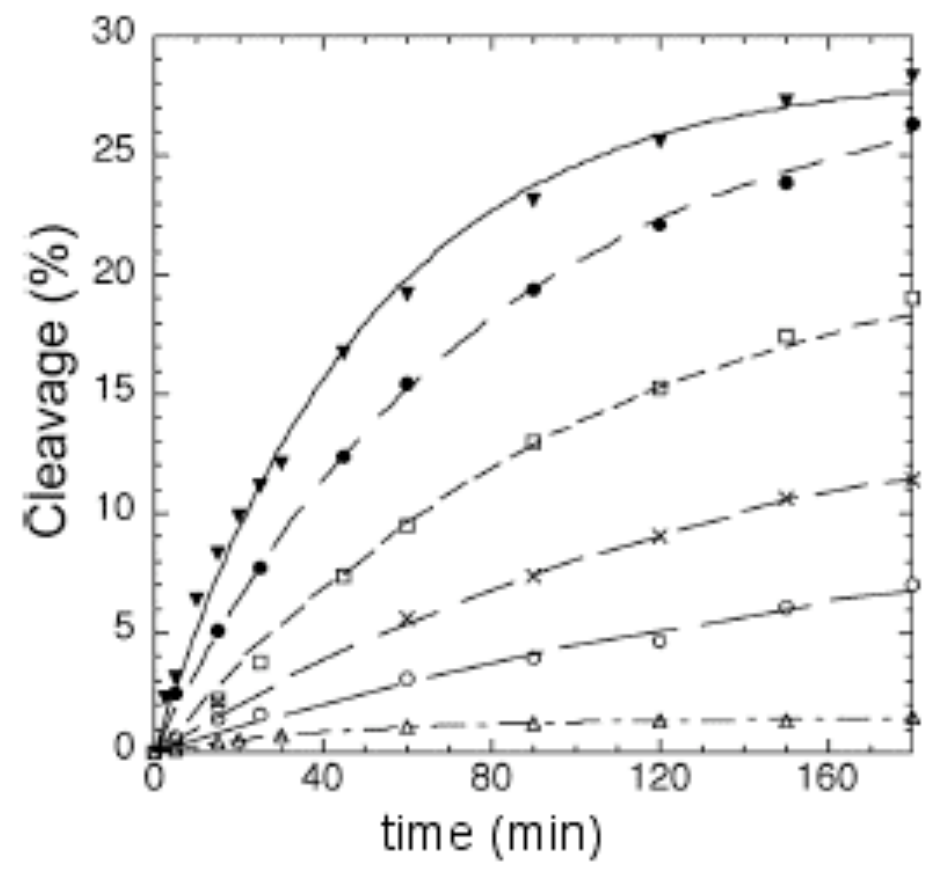

\section{Figure 2}

Kinetics of the ribozyme reaction as a function of pressure. The ribozyme reaction was followed as indicated in text under various pressures. From top to bottom: $0.1 \mathrm{MPa}$ (atmospheric pressure) (closed triangles), $25 \mathrm{MPa}$ (closed circles), $40 \mathrm{MPa}$ (open squares), $75 \mathrm{MPa}$ (crosses), $120 \mathrm{MPa}$ (open circles) and $200 \mathrm{MPa}$ (open triangles). The experimental conditions were previously described (35). The kinetics were fitted to the exponential equation: $\mathrm{x}=\mathrm{x}^{\mathrm{eq}}\left(1-\mathrm{e}^{-\mathrm{k} . \mathrm{t}}\right)$, where $\mathrm{x}^{\mathrm{eq}}$ is the fraction of cleaved RNA at equilibrium, $\mathrm{x}$ the fraction of cleaved RNA at time $t$ and $k$ the observed cleaving rate constant. 

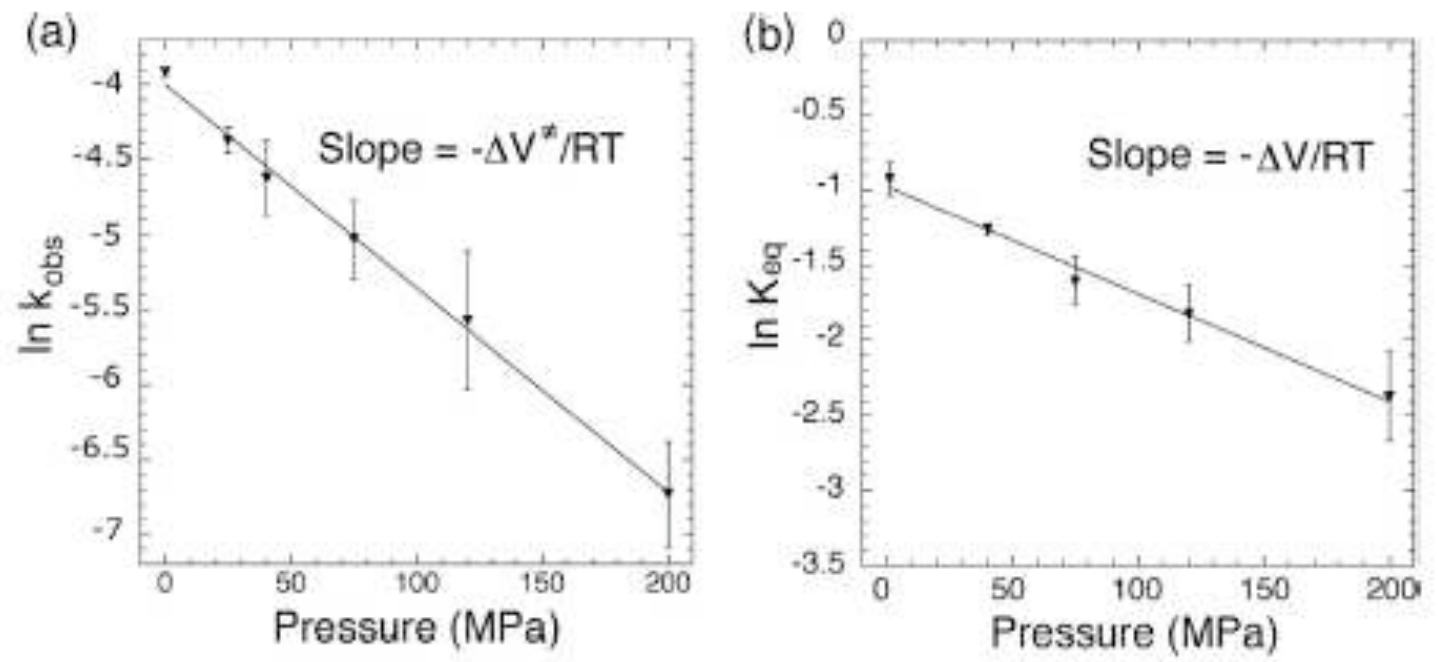

\section{Figure 3}

Determination of the volume changes associated to the ribozyme reaction. a: The values of the rate constant were extracted from the kinetics presented in figure 2 . The $\Delta \mathrm{V}^{\neq}$of activation was calculated from the slope of the curve $\ln \mathrm{k} /$ pressure; $\mathrm{b}$ : In a similar way, the $\Delta \mathrm{V}$ of the reaction was calculated from the slope of the curve $\ln \mathrm{K} /$ pressure.

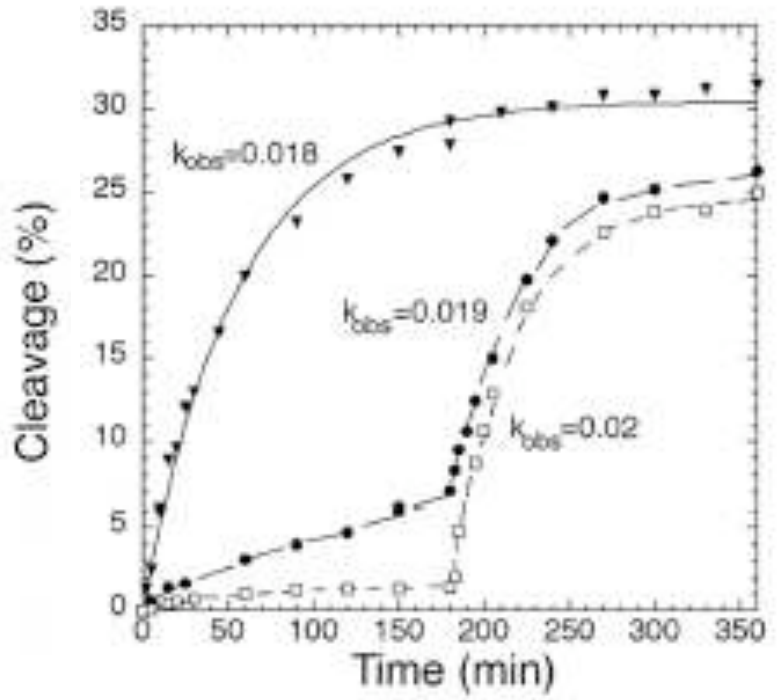

\section{Figure 4}

Reversibility of the pressure effect. The reaction was followed at $0.1 \mathrm{MPa}$ (closed triangles), $120 \mathrm{MPa}$ (closed circles) and $200 \mathrm{MPa}$ (open squares). After three hours of reaction, the samples were brought back to atmospheric pressure and the reaction was followed for three more hours. The observed rate constants $\left(\mathrm{k}_{\mathrm{obs}}\right.$ per minute) are indicated for each sample at atmospheric pressure. 

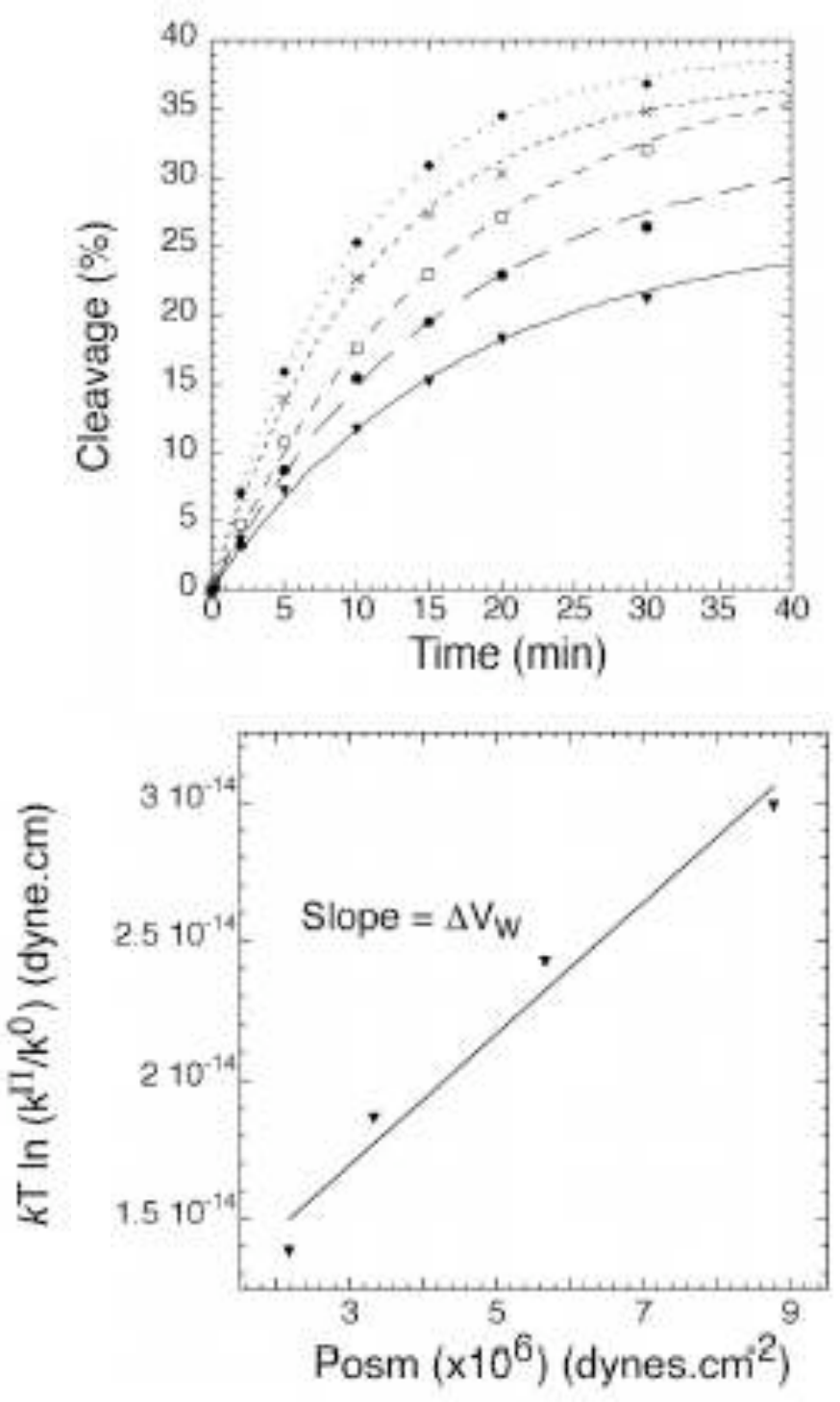

\section{Figure 5}

Influence of the osmotic pressure on the rate of the ribozyme reaction. a: The reaction was followed in the absence and presence of various concentrations of polyethyleneglycol 400. From bottom to top: 0 (closed triangles), $2.5 \%$ (closed circles), $5 \%$ (open squares), $7.5 \%$ (crosses) and 10\% (closed diamonds); b: The number of water molecules released during the reaction was calculated from the slope of the variation of kT $\ln \left(\mathrm{k}^{\Pi} / \mathrm{k}^{0}\right)$ as a function of osmotic pressure; $\mathrm{k}$ is the boltzman constant, $\mathrm{T}$ the absolute temperature, $\mathrm{k}^{\Pi}$ and $\mathrm{k}^{0}$ the rate constants of the reaction under osmotic stress and under the controle conditions respectively. 
This manuscript has been accepted for publication in Biochimica et Biophysica Acta doi :10.1016/j.bbapap.2006.01.020

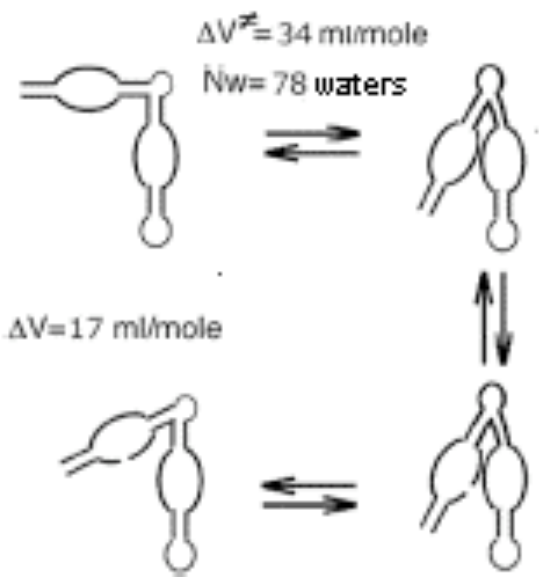

\section{Figure 6}

Volume and hydration changes during the ribozyme cleavage reaction. a: open uncleaved conformation; b: docked transition state; c: cleaved docked state; d: cleaved open state. 